\title{
A produção escrita do gênero e-mail nos livros didáticos de língua inglesa
}

The written production of e-mail genre in English textbooks

\author{
Sílvia Mônica Moura Lima*
}

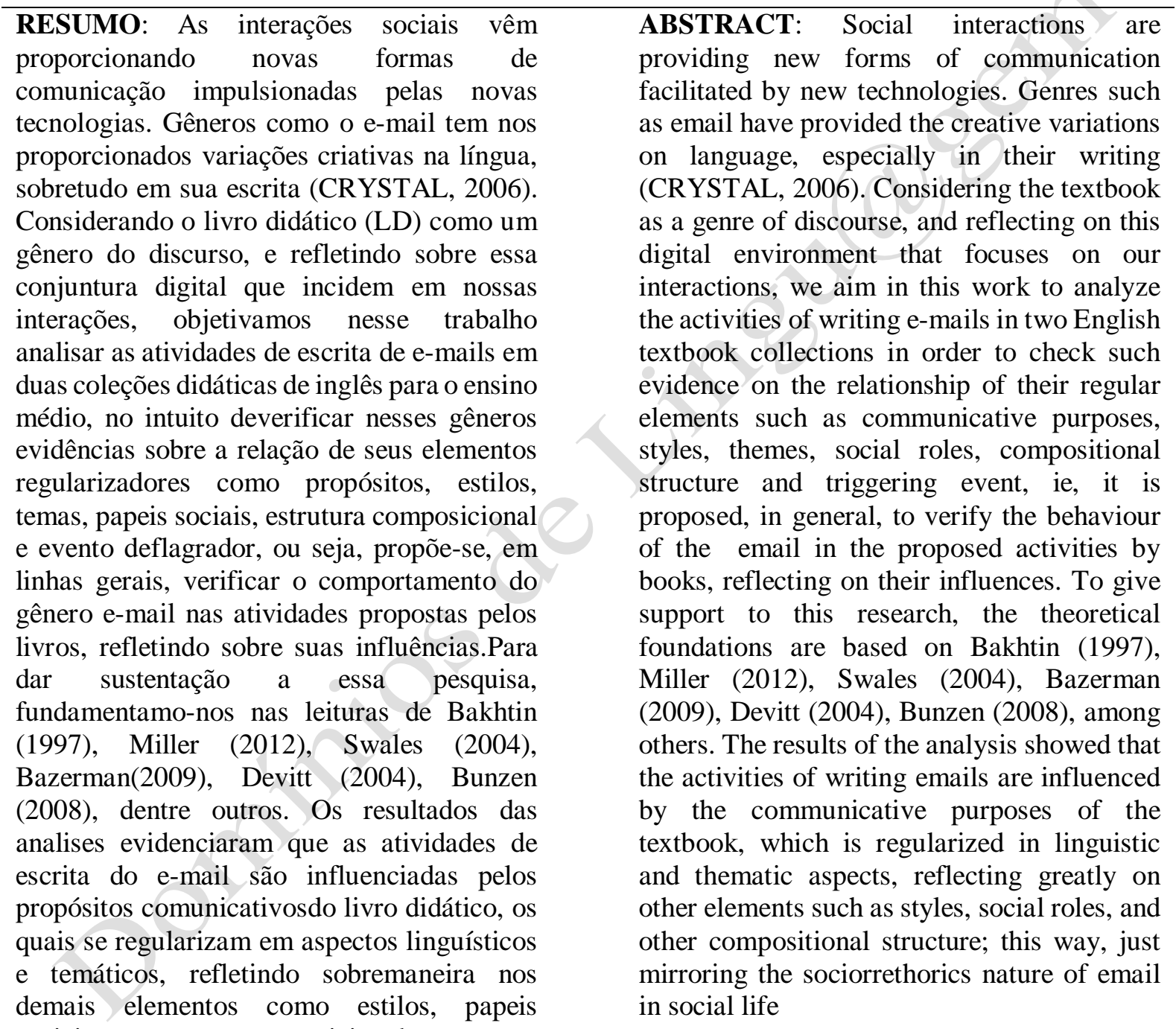
sociais, estrutura composicional e outros, dessa maneira, pouco espelhandoa natureza sociorretórica do e-mail na vida social.

PALAVRAS-CHAVE: E-mail. Livro KEYWORDS: E-mail. Textbook. English. didático. Inglês. Gênero. Influências. Genre. Influences.

\footnotetext{
* Estudante do Mestrado Acadêmico em Letras da Universidade Federal do Piauí.
} 


\section{Considerações iniciais}

Atualmente, vivenciamos práticas cada vez mais plurais intensificadas pelas novas tecnologias e internet. Juntos, esses instrumentos têm repercutido em novas formas de construção de sentido e interlocução que, por conseguinte, fazem repensar sobre o processo enunciativo, sobretudo as configurações pragmáticas dos gêneros que confluem o ambiente digital.

O e-mail é um desses meros exemplos. Por ser um gênero que conduz trocas discursivas entre seus usuários na internet, proporcionam diretamente a criatividade e a variabilidade linguística, pois, em geral, são escritos sem uma monitoração e simplificados por expressões típicas da escrita virtual (CRYSTAL, 2006).

Mediante essas circunstâncias sobre o comportamento dos usuários em sua escrita na tela, direcionamo-nos à escola, pois nesse meio espera-se que o processo de ensino e aprendizagem alicerce-se no estudo sociointerativo da língua, isto é, de modo que contextualize os usos reais de gêneros. Crystal (2006, p. 2) nessa linha de pensamento, demonstra sua preocupação sobre a possível mudança de perspectiva de ensino de letramento e ortografia, em geral, voltados à norma culta diante de "padrões relaxados de e-mails” e outros gêneros digitais. Semelhantemente, Marcuschi (2010, p. 19) expõe também o cuidado que a escola deverá tomar ao tratar o ensino de gêneros da esfera digital como a produção de um e-mail.

Em seu próprio texto, Marcuschi pontua que essa reflexão já se constata nos manuais didáticos do ensino fundamental. Semelhantemente, no ensino médio, sobretudo na seção sobre línguas estrangeiras, há orientações para que a educação de alguma forma propicie a reflexão sobre os usos criativos da linguagem no meio digital, conforme as Orientações Curriculares para o Ensino Médio (2006, p.105).

Considerando os gêneros como ações sociais tipificadas que atuam por propósitos comunicativos (SWALES, 2004), definimos o e-mail como um gênero digital. Portanto, sabendo que seu local de atuação é na virtualidade, refletimos que quando inserido em outros gêneros como o livro didático, o e-mail pode sofrer modificações significativas (BUNZEN, 2008).

Destarte, direcionamo-nos aos livros didáticos: de que maneira, os livros propõem o ensino de gêneros? Os propósitos nas atividades de escrita de $e$-mail proporcionam finalidades recorrentes àquelas do e-mail no espaço virtual? 
Apoiando-nos na reflexão que Miller (2012, p.44) faz sobre o direcionamento do ensino de gêneros na escola, cuja preocupação deva ir além da forma, mas servir como “chaves para a compreensão de como participar nas ações de uma comunidade”. E repensando sobre os variados eventos comunicativos digitais que participamos, objetivamos neste trabalho analisar as atividades de escrita de e-mails em duas coleções didáticas de inglês para o ensino médio, no intuito de verificar nesses gêneros evidências sobre a relação de seus elementos regularizadores como propósitos, estilos, temas, papeis sociais, estrutura composicional e evento deflagrador.

Desse modo, propõe-se, em linhas gerais, verificar o comportamento do gênero $e$-mail nas atividades propostas pelos livros, refletindo sobre suas influências. Afinal, compreendemos que o ensino de gêneros na escola necessita se basear em suas ações sociais recorrentes. Para isso, nos tópicos subsequentes, discutiremos sobre o gênero e-mail enquanto ação social e seus reflexos no livro didático.

\section{Gênero digital e-mail como ação social}

Seguindo o pensamento dialógico de Bakhtin (1997) toda comunicação só é possível por meio de algum gênero discursivo. Ao refletirmos sobre a atualidade, podemos constatar que nossa capacidade comunicativa tem se ampliado significativamente perante os usos tecnológicos e suas possibilidades interativas. Podemos postar bater papo, enviar e-mails, torpedos etc. Ao tratarmos desse assunto consideramos importante citar a visão repercutida por Kenski(2003, p. 21):

A evolução tecnológica não se restringe apenas aos novos usos de determinados equipamentos e produtos. Ela altera comportamentos. A ampliação e banalização do uso de determinada tecnologia impõem-se à cultura existente e transformam não apenas o comportamento individual, mas o de todo o grupo social.

Cada tecnologia nova criada e aceita pela sociedade refrata no comportamento das pessoas. Hoje, vivenciamos variadas formas de comunicação via tecnologias e isso tem influenciado na configuração de muitos gêneros, definhando alguns, e aflorando outros, muitas vezes evoluídos de outros prévios (BAKHTIN,1997; MILLER, 2012; MARCUSCHI,2010).

A partir dessa premissa, valoramos o conceito de gênero defendido por Bazerman (2009, p.11) como uma “categoria essencialmente sócio histórica, sempre em mudança”, não sendo assim “cristalizações formais no tempo". 
O termo e-mail é uma palavra emprestada da língua inglesa, mas já dicionarizada e se refere tanto a mensagem eletrônica enviada por um provedor quanto ao provedor e endereço digital. Como correio eletrônico (provedor) é uma ferramenta que possibilita a comunicação a partir da troca de mensagens virtuais entre os usuários via web. Podemos dizer que o correio eletrônico é o suporte encarregado de enviar a mensagem (gênero textual). Logo, torna-se importante dizer que esse artigo direciona-se a estudar o $e$-mail, enquanto gênero digital e não suporte.

Para o definirmos como gênero, embasamo-nos na concepção sociorretórica de Miller (2012, p.32): "gêneros como ações sociais tipificadas fundadas em situações recorrentes”. Nesse aspecto, consideramo-lo como enunciações provenientes da interação humana que recorrem dentro de uma situação retórica, fundamentando-se em um motivo para agir daquela maneira em sociedade.

A concepção bakhtiniana de gêneros secundários também nos faz olhar o e-mail como um gênero da esfera digital, pois seria o hibridismo de outros já existentes, que de certa forma mantém semelhanças com os novos. Assim, podemos relacionar as semelhanças que o e-mail mantém com a carta e o bilhete. Essa característica também explica a ligação do gênero com seu contexto de outros gêneros (DEVITT, 2004, p.27), pois outros similares exerceriam influências sobre o e-mail. Por essa razão, trataremos a seguir sobre os seus elementos caracterizadores.

\subsection{Elementos Caracterizadores do Gênero}

Para compreendermos o gênero como uma ação social, precisamos atentar para sua dinâmica interna. Se um dos elementos é alterado, isso repercute no gênero como um todo, pois as escolhas que fazemos quando interagimos com alguém são influenciadas pelo seu conteúdo e forma fundidos (MILLER, 2012; BAKHTIN, 1997), em outras palavras, por todos os elementos que repercutirão nas escolhas estilísticas e formais do gênero.

\subsubsection{Evento deflagrador}

O evento deflagrador corresponde ao estímulo que nos leva a interagir sociodiscursivamente com alguém, expressando-se por um determinado texto ou gênero 
(PARÉ; SMART, 1994 apud Alves Filho, 2001, p. 40). Podemos dizer que não temos uma relação aleatória com os gêneros, pois somos impulsionados a utilizá-los segundo atitudes individuais, mas que possuem efeitos regulares em sociedade. O e-mail na vida real possui uma variedade regular de eventos deflagradores. Elencá-los seria uma tarefa difícil, devido sua diversidade, mas podemos ilustrar alguns como: chamada para publicação; reunião; divulgação de um produto ou serviço, dúvidas de alunos etc. Salientamos que assim como outros elementos, o evento deflagrador dependerá dos propósitos e papeis sociais dos participantes envolvidos na interação.

\subsubsection{Tema}

Ainda que para o senso comum o tema seja tratado como o assunto de cada texto, o tema ou conteúdo temático, conforme Bakhtin (1997 [1979]), não se restringe somente a isso. Na verdade, o tema possui valor discursivo, uma "orientação de sentido específica para com ele e os outros participantes da interação” (RODRIGUES, 2005, p.167). Isso significa dizer que carrega consigo os assuntos recorrentes falados entre pessoas por determinados gêneros. De acordo com Alves Filho (2011, p. 44-45), por possuir sentidos regulares, o tema dos gêneros é bastante previsível, e nos ajuda a criar expectativas sobre o gênero que lidamos na comunicação, sendo inclusive possível depreender os implícitos como na piada ou na sátira.

Embora reconheçamos que os sentidos dos temas possam variar enunciativamente, pois são frutos de uma estabilidade relativa (BAKHTIN, 1997[1979], essa mudança não ocorre de maneira individual, mas coletiva. Se “os próprios gêneros 'modulam' a maior ou menor possibilidade de tratamento exaustivo do objeto e do sentido na interação” (RODRIGUES, 2005, p. 167), podemos compreender que a interação dependerá do repertório de gêneros de que a pessoa participa ou conhece. Em relação ao e-mail, o tratamento conferido ao tema, na maioria das vezes é realístico, mas dependendo dos propósitos e dos papeis sociais envolvidos pode variar. Podemos exemplificar melhor, quando enviamos ou recebemos uma mensagem piada, há nele um tratamento pejorativo, assim como na mensagem de propaganda poderá haver um tratamento fantasioso, ficcional, já o institucional poderá ser neutro etc., cada um, portanto possuindo suas tipicidades.

\subsubsection{Estrutura composicional}

Quando Bakhtin (1997, p. 279) define o gênero como formações enunciativas com relativa estabilidade, afasta-se de um conceito formalístico. Se analisarmos que “o enunciado 
reflete as condições específicas e as finalidades de cada uma das esferas”, e que nos comunicamos por gêneros, podemos inferir que a estrutura composicional dependerá de cada esfera, não sendo rígida ou estática. Ela não age sozinha no enunciado, na verdade, funde-se ao estilo e conteúdo, dando características típicas que dependerão das especificidades de cada grupo social.

Logo, a estrutura composicional tem seu aspecto formal, mas não se resume a isso, pois integra o enunciado e as escolhas estilísticas e conteudistas de seus participantes. A estrutura composicional é flexível, pois é construída por diferentes grupos que podem possuir suas particularidades, mas dentro de cada grupo a estrutura ganha formas típicas e, portanto, reconhecíveis. Vejamos o comentário que Bakhtin (1997, p.302) faz sobre a estrutura:

Aprendemos a moldar nossa fala às formas do gênero e, ao ouvir a fala do outro, sabemos de imediato, bem nas primeiras palavras, pressentir-lhe $o$ gênero, adivinhar-lhe o volume (a extensão aproximada do todo discursivo), a dada estrutura composicional, prever-lhe o fim, ou seja, desde o início, somos sensíveis ao todo discursivo que, em seguida, no processo da fala, evidenciará suas diferenciações.

A estrutura composicional, consequentemente, passa a ser significada em contexto. O tom de voz, as escolhas linguísticas passam a ter valor durante a interação, e os envolvidos passam a ser reconhecidos por sua atitude responsiva ativa, pois interagem com as intencionalidades do enunciador. No tocante ao e-mail, sua estrutura não é fixa, mas apresenta estabilidade conforme o estilo do autor e principalmente para quem é dirigida a mensagem. Quando recebemos o e-mail de alguém que mantém conosco uma relação circunstancial, convenientemente, utilizamos traços formais da língua para que os objetivos sejam atendidos fazendo uso da estrutura: vocativo, saudação, mensagem, despedida e assinatura. Caso os participantes sejam amigos, esta regularmente possui menor monitoração ortográfica e um estilo mais informal e pessoal. Mas, isso não é uma regra geral, já que a estrutura composicional do e-mail é maleável, pode se diferenciar nas trocas de turno, nos participantes envolvidos e propósitos, que repercutirão nos estilos escolhidos pelo interlocutor para elaborar a mensagem.

\subsubsection{Estilo}

O estilo refere-se ao "uso típico de recursos lexicais, fraseológicos e gramaticais da língua” (RODRIGUES, 2005, p.168). Embora, toda pessoa tenha seu estilo próprio, individual, o gênero carrega em si sua regularidade que pode variar dependendo do gênero e da esfera. A 
esfera literária, por exemplo, apresenta uma maior manifestação estilística individual, no sentido de ser mais individualizada, pois se insere nos propósitos de seus interagentes, que fazem do gênero uma manifestação artística. Entretanto, outros gêneros já são menos maleáveis, como certidões de nascimento e os ofícios que exigem uma padronização da escrita.

A variabilidade dos gêneros do discurso decorre porque cada esfera possui suas regularidades estilistas linguísticas ou funcionais, pois há uma relação entre o estilo, unidade temática, conteúdo, e das relações entre os participantes. Isso se justifica porque as estratificações linguísticas provenientes de esferas têm forças sociais significativas (RODRIGUES, 2005, p.168), por exemplo, a esfera jornalística e a esfera de agricultores, cada um possui seu repertório de gêneros conforme suas necessidades sociais, e nisso implica também suas escolhas estilísticas. Conforme Bakhtin (1997, p. 285), as mudanças estilísticas decorrentes da própria evolução da língua repercutem nos gêneros, e assim podemos nos reportar aos digitais, em que observamos a criatividade linguística, suas variabilidades decorrentes da evolução mediante novas formas de interação, e que em sua maioria dependem dos propósitos e dos participantes envolvidos, como no e-mail.

Segundo Marcuschi (2010, p.17), a “cultura eletrônica” conduz a uma "nova economia da escrita”. O uso de expressões abreviadas, siglas, uma linguagem menos preocupada com a ortografia ou com as regras normativas da gramática é comum principalmente quando estamos interagindo com familiares e amigos. Entretanto, devemos ressaltar que o estilo da escrita no $e$ mail dependerá da relação entre participantes envolvidos, da hierarquia entre eles, do evento deflagrador, dos propósitos e dos temas, pois a escrita pode passar a ser monitorada, até mesmo porque alguns provedores possuem a função rascunho e até corretor ortográfico.

\subsubsection{Papeis Sociais}

O processo enunciativo nunca ocorre numa lacuna social. Segundo, Bakhtin/Volochinov (1992, p. 112 apud MENEGASSI, 2011, p.170), enunciamos sempre para alguém. Na verdade, a interação envolve sempre um locutor e um interlocutor. Os papeis sociais são as funções desempenhadas pelos interlocutores dos gêneros durante o processo de escrita e leitura (ou fala e escuta). Segundo Paré e Smart (1994 apud CARVALHO, 2005, p.136), os papeis sociais, além de outros elementos, são regularizadores da escrita dos gêneros, e indicam os graus de interação entre os interlocutores, sua hierarquia, o poder que alguns podem ter ou limitações de acordo com as relações sociais (CARVALHO, 2010, p. 137). Além disso, os 
papeis determinam segundo a situação social, a forma como os interlocutores agirão enunciativamente (BAKHTIN/VOLOCHINOV, 1992, p. 114 apud MENEGASSI, 2011, p.171). Em relação ao gênero $e$-mail, os interlocutores são reais, mas mantêm posturas variadas e algumas relações são assimétricas, como entre empregador e empregado, e outras são simétricas como acontece entre amigos.

\subsubsection{Propósito comunicativo}

Desde que o novo movimento de estudos retóricos passou a vigorar, no início da década de 80, a visão de gêneros passou a ser, repercutidamente, compreendida por suas finalidades ou propósitos comunicativos, (ASKENHAVE; SWALES, 2001, p. 195). Todo gênero discursivo é motivado por um ou mais propósitos. Em consonância com a teoria retórica de gêneros, Swales (1990, p. 58, apud Pires, 2012, p.47) prima sobre a importância dos propósitos comunicativos para a recorrência dos gêneros:

Uma classe de eventos comunicativos, cujos exemplares compartilham os mesmos propósitos comunicativos. Esses propósitos comunicativos são reconhecidos pelos membros mais experientes da comunidade discursiva original e constituem a razão do gênero. [..]Além do propósito, os exemplares do gênero demonstram padrõessemelhantes mas com variações em termos de estrutura, estilo, conteúdo e público alvo.

Logo, o propósito comunicativo norteia não só o gênero, mas todos os seus elementos, inclusive o conteúdo e o estilo, (BIASI-RODRIGUES,2007, p.730) direcionando, assim, a ação retórica. Podemos definir os propósitos de um gênero como as finalidades ou as motivações sociais que fazem com que um grupo de pessoas utilize certas tipificações sociodiscursivas em determinadas situações (ALVES FILHO, 2011, p. 34). E como toda motivação é situada no gênero, temos que "os gêneros seriam o elo entre as intenções privadas e as exigências sociais" (PIRES, 2012, p.50).

É necessário esclarecer que os propósitos poderão ter um enfoque diferente, se analisarmos os papeis desempenhados pelos atores. Segundo Alves Filho (2011, p. 35), existem duas perspectivas em que propósitos ocorrem: do ponto de vista de quem os elabora, seu locutor ou daquele que os observa ou lê. No gênero e-mail, podemos observar esses diferentes propósitos, pois diariamente recebemos convites, propagandas, e-mail de amigos, etc. Ademais, para Bathia (1993, 1997 apud Bezerra, 2009, p.466), quando utilizamos um gênero, incorporamos propósitos específicos ou “intenções particulares” que podem ser tanto de produtores quanto controladores de sua produção e circulação. Nessa perspectiva, pode haver 
propósitos implícitos ou secundários que estimulem um gênero agir diferenciadamente em determinada esfera, principalmente, quando aquele se encontra em outro suporte ou em outros gêneros.

\subsubsection{Contextos de situação, cultura e outros gêneros}

Devitt (2004, p.25), ecoando a concepção de gêneros realizada por Miller (2012) e a ampliando, considera que existem três tipos interligados de contextos: o de situação, o de cultura, e de outros gêneros. A situação estimulada por um motivo é essencial para a interpretação do gênero, pois quando tipificada estabelece formas convencionais, que regulam outras necessidades. Essa regularidade se deve porque ao participarmos de uma situação de interação, baseamo-nos em situações análogas por determinados gêneros, pois, ativamos nossos estoques de conhecimentos dos tipos de situações que já vivenciamos e sabemos agir retoricamente em sociedade, embora saibamos que novas podem surgir pela própria fluidez de nossas interatividades sociais.

A cultura é justificada por envolver um compartilhamento de contextos materiais e comportamentais, embebidos por crenças, valores e ideologias de determinadas esferas sociais, logo, passa a definir como agir em determinados contextos de situações, mediante os propósitos e os atores envolvidos. O contexto cultural justifica o porquê de alguns gêneros agirem daquela forma em esferas específicas.

"Ninguém escreve ou lê num vácuo”, há nesse ínterim, um contexto de gêneros existentes, similares ou prévios que exercem influências uns sobre os outros (DEVITT, 2004, p.27). Isso explica a própria evolução que ocorrem nos gêneros, pois, conforme Alves Filho (2011, p. 56), quando os visualizamos em situações reais, percebemos que "respondem uns aos outros, complementam-se, rivalizam entre si ou servem como referência para o surgimento de novos gêneros.” Para Devitt, portanto, os gêneros são interligados em três contextos, de maneira que todos incorporam-se dinamicamente, embora reconheça que exista um nivelamento entre eles. Nesse sentido, consideramos que o e-mail funciona nessa interligação contextual entre situação, cultura e outros gêneros que refletirão na sua produção.

\section{Livro didático: um gênero do discursivo}

Seguimos o entendimento de Bakhtin (2003, p. 281) sobre o quanto os gêneros evoluem. De acordo com o autor, os gêneros primários como o diálogo seriam as primeiras 
regularizações que estabelecemos discursivamente. Mas, esses gêneros podem se tranformar e adquirir características particulares dentro de outros gêneros, seus secundários. O telefonema e o e-mail seriam exemplos. Igualmente, apoiamo-nos no raciocínio apresentado por Todorov (1980,p. 264 apud Buzen, 2008,p. 7) em que defende que “ um gênero surge de outros gêneros, um gênero é sempre a transformação de um ou vários gêneros antigos por inversão, por deslocamento, por combinação”.

Concordamos também com Devitt (2004, p.27) ao afirmar que os gêneros exercem influências entre si, pois carregam traços de outros. Por essa razão, acreditamos que o livro didático (doravante LD) seja um gênero do discurso, pois constrói-se enunciativamente a partir das escolhas de seu interlocutor, autor do livro, direcionando-se aos interlocutores, alunos e professores. Buzen (2008, p. 7) explica melhor como a inserção de outros gêneros no LD não o transforma em um suporte:

Assim, quando os autores e editores do LDP [livro didático de português] selecionam/negociam determinados objetos de ensino e elaboram um livro didático, com capítulos e/ou unidades didáticas (organizados por seções didáticas regulares, pois tem uma inter-relação com a proposta pedagógica), eles estão produzindo um enunciado relativamente estável, cuja função social é de (re)apresentar, para cada geração de professores e estudantes, o que é oficialmente reconhecido ou autorizado como forma de reconhecimento sobre a língua(gem) e sobre as formas de ensino-aprendizagem.

Espelhados por essa visão, compreendemos que as coleções didáticas analisadas são gêneros discursivos e que estas trazem influências para os gêneros inseridos propostos nas atividades. Sabemos que os propósitos do autor do livro perpassam por instruções e regimentos, os quais selecionam os melhores qualificados de acordo com seus parâmetros, e manuais como $\mathrm{PCN}^{+}{ }^{1}, \mathrm{OCEM}^{2}$, e guias do Programa Nacional do Livro Didático (PNLD) e isso reflete na construção do gênero LD e sua estabilidade. Nesse sentido, as obras analisadas por esse artigo foram avaliadas pelo PNLD (2012-2014), que conforme o seu edital PNLD (2012, p.25), tiveram como critérios em relação ao gênero:

(2) contempla variedade de tipos e gêneros de texto, de linguagens verbal e nãoverbal, de variações linguísticas, caracterizadoras de diferentes formas de expressão na língua estrangeira e na língua nacional;

(3) seleciona textos autênticos e originais, oriundos de diferentes suportes e espaços sociais de circulação das comunidades que se manifestam na língua estrangeira;

(10) propõe atividades de produção escrita como processo de interação, que exige a definição de parâmetros comunicativos, bem como o entendimento de que a

\footnotetext{
${ }^{1}$ Parâmentros Curriculares Nacionais para o Ensino Médio.

2 Orientações Curriculares Nacionais para o Ensino Médio.
} 
escrita se pauta em convenções relacionadas a contextos e gêneros de texto, e deve estar submetida a constante processo de reelaboração.

Interessa-nos saber de que maneira as coleções analisadas propõem a utilização do gênero e-mail. Teriam essas um enfoque linguístico, ou seja, focalizado nas "estruturas léxicogramaticais e retórica dos propósitos comunicativos”, de modo que o aluno pudesse perceber as formas mediante as situações e os propósitos do gênero, ou por um enfoque retórico,focalizado mais no contexto situacional, nos propósitos comunicativos, nas funções dos gêneros, e em atitudes, crenças e valores? (FLOWERDEWB, 2002, p. $91-92$ apud ALVES FILHO, 2011, p. 67).

\section{Metodologia}

Fundamentamo-nos na concepção de gêneros segundo Bakhtin (1997), em que observamos o LD como um conjunto de enunciados relativamente estáveis. Assim, propomos, nesse artigo, compreender como são delineadas as atividades de escrita do gênero $e$-mail em duas coleções didáticas. Para isso, resolvemos fazer uma análise contrastiva entre o e-mail inserido em nossas práticas comunicativas reais, e as simulações de escrita de $e$-mail pelos livros, baseando-nos na prerrogativa de que o ensino de gêneros deva refletir as funções sociais regulares de nossas interações (MILLER, 2012).

Diante disso, voltamos o nosso olhar para as seguintes categorias de análise: evento deflagrador (ALVES FILHO, 2011), objetivando descobrir quais os estímulos que as atividades de escrita impulsionam o aluno para a elaboração do e-mail; tema, estrutura composicional e estilo (BAKHTIN, 1997), buscando compreender sob que temáticas, estruturas e estilos as atividades planejam a elaboração do e-mail; papeis sociais, analisando o grau interativo entre os interlocutores, bem como os propósitos comunicativos, objetivando compreender as finalidades em fazer com que o aluno produza o e-mail (SWALES,1990).

Os nossos corpora constituem-se de sete atividades de escrita do gênero e-mail, assim distribuídos: três, na coleção On Stage, e quatro, na coleção English for All. A escolha desse corpus justifica-se por serem uma das primeiras coleções aprovadas destinadas ao ensino público, segundo os critérios do PNLD (2012-2014). Consonante, Araújo (2012, p. 146) acredita que o LD de língua inglesa tem ostentado um valioso papel para o contexto educacional, sobretudo para o Ensino Médio:

Esse material didático assume um papel de sujeito 'ativo' que conduz o professor a selecionar o conteúdo de forma linear e sequencial, definindo, 
também, a maneira de o professor desenvolver as atividades didáticas e a metodologia de ensino. O livro didático, então, assume por vezes o lugar do professor, constituindo-se referência organizadora do currículo escolar, além de anular a 'voz' do professor.

Portanto, destaca-se a necessidade de compreender como o processo de ensino e aprendizagem de língua inglesa norteia-se pelos livros,refletindo se as mesmas baseiam-se nas funções comunicativas reais e nas teorias contemporâneas de gêneros.Para facilitar a discussão dos dados, resolvemos enumerar cadaatividade de escrita de $e$-mail: de 1 a 3 para a coleção $O n$ Stage e de 4 a 7 para coleção English for All.

\section{Análises}

Sabendo que o e-mail possui regularidades mediante os usos sociais que fazemos do mesmo na Internet. Realizamos uma analise comparativa entre o gênero e-mail da vida real, e o gênero e-mail no LD, motivados pela necessidade de compreender como esse gênero digital possa sofrer influências ao ser materializado num gênero impresso. Contemplando o LD como um gênero, Bakhtin/Volochinov (1997, p. 123 apud SOUZA; VIANA, 2011, p.5) comentam sobre o mesmo:

O livro, isto é, o ato de fala impresso, constitui igualmente um elemento da comunicação verbal. Ele é objeto de discussões ativas sob a forma de diálogo e, além disso, é feito para ser apreendido de maneira ativa, para ser estudado a fundo, comentado e criticado no quadro do discurso interior, sem contar as reações impressas, institucionalizadas, que se encontram nas diferentes esferas da comunicação verbal (críticas, resenhas, que exercem influência sobre os trabalhos posteriores, etc.). Além disso, o ato de fala sob a forma de livro é sempre orientado em função das intervenções anteriores na mesma esfera de atividade, tanto as do próprio como as de outros autores[...]

Verificamos claramente a categorização do livro como um gênero complexo para Bakhtin/Volochinov (1997), e isto é tanto verdade, quando percebemos que o "manuais dos professores" (guias dos livros que dedicam a comentar sobre como se desvelam as obras, bem como a dar orientações aos professores) evocam a construção de seus enunciados relativamente estáveis, mediante suas escolhas na elaboração dos livros. Logo, os dois manuais amparam-se nos documentos oficiais norteadores, e apresentam que a abordagem da língua ocorre pela integração das quatro habilidades (ler, ouvir, falar e escrever) de maneira sociointeracional, baseando-se nos usos sociais que fazemos dos mesmos. Ademais, expõem que as atividades refletem os acontecimentos contemporâneos e temas reais que propiciem a cidadania do aluno (MARQUES,2010; AUN; MORAIS; SANSANOVICZ, 2010). Nessa perspectiva, cada 
unidade desdobra-se sobre um tema que repercutirá em todos os textos que englobam a mesma. Algumas outras considerações relacionadas aos manuais, discutiremos nas análises propriamente ditas.

\subsection{Evento deflagrador}

A identificação do evento deflagrador é profícua para uma abordagem de línguas em sala de aula que objetiva simular as situações reais em que os gêneros são produzidos para determinadas ações estabelecidas em sociedade. Conforme Alves Filho (2011, p.40), esse pode “indicar claramente o ponto de partida para a escrita de um texto”. No trabalho com gêneros em sala de aula, deve-se observar seus usos sociais, para que não ocorra que o evento destoe da realidade do gênero na vida social. Nesse sentido, vejamos as regularidades nas duas coleções:

Quadro 1: Regularidades sobre o evento deflagrador.

\begin{tabular}{|l|l|}
\hline \multicolumn{1}{|c|}{ LD “On stage” } & \multicolumn{1}{c|}{ LD “ English for all” } \\
\hline $\begin{array}{l}\text { Atividade 1:A necessidade de responder uma } \\
\text { mensagem para uma amiga que pede ajuda numa } \\
\text { pesquisa escolar sobre Santos Dummont; }\end{array}$ & $\begin{array}{l}\text { Atividade 4: Novidade sobre a hospedagem de } \\
\text { um amigo estrangeiro na sua casa; }\end{array}$ \\
\hline $\begin{array}{l}\text { Atividade 2: A necessidade de responder o e-mail de } \\
\text { uma amiga na sua pesquisa de geografia; }\end{array}$ & $\begin{array}{l}\text { Atividade 5:Sugestão de uma pauta sobre um } \\
\text { atleta; }\end{array}$ \\
\hline $\begin{array}{l}\text { Atividade 3: A necessidade de responder uma amiga } \\
\text { e ajudá-la em sua pesquisa sobre uma frase célebre de } \\
\text { Einstein }\end{array}$ & $\begin{array}{l}\text { Atividade 6:Convite para um amigo que está de } \\
\text { férias ; }\end{array}$ \\
\cline { 2 - 2 } & Atividade 7:Convite para uma festa; \\
\cline { 2 - 2 }
\end{tabular}

\subsubsection{Evento deflagradores e a temática das unidades didáticas}

Analisando os eventos deflagradores das atividades 1,2 e3 percebemos que buscam envolver a interdisciplinaridade em todas as atividades, e isso foi ressaltado em seu manual (MARQUES,2010, p.4). Nesse sentido, constatamos que o evento deflagrador para o gênero $e$ mail é comum a todas as atividades de produção do mesmo: necessidade de responder uma mensagem para uma amiga na sua pesquisa escolar. É um evento recorrente para a coleção, e factível na vida real, mas não tão comum para ocorrer em três atividades o mesmo evento, pois normalmente recebemos mensagens variadas com eventos que deflagram diferentemente nas mensagens eletrônicas, como: chamada para publicação; reunião; divulgação de um produto ou serviço, dúvidas de alunos etc. Nesse sentido, o evento deflagrador foi impulsionado a temática de cada unidade, assim como nas atividades 4, 5, 6 e 7 (coleção English for All) contudo, nessas últimas percebemos que apresentaram uma diversificação de eventos deflagradores. Segundo 
Dell’Isola (2007, p.13 apud Aguiar, 2012, p. 40), “a decisão de se trabalhar com os gêneros exige preparo e merece cuidado para não se cristalizar a ideia de que cada gênero tem uma forma fixa, imutável e circula em um único domínio discursivo”, portanto, consideramos que as atividades 4 a 7 contemplam a diversidade como como na prática cotidiana do $e$-mail.

\subsection{Tema}

O tema refere-se a algo que predizemos quando nos deparamos com um gênero devido a seus sentidos regulares e valor discursivo em gêneros específicos, cf. Bakhtin (2003 [1979]). Assim, na abordagem de línguas em sala de aula, é proeminente que as atividades de leitura e escrita espelhem-se em situações reais, pois os alunos, mediante seus repertórios, podem ativar seus esquemas relacionados ao gênero específico e utilizar apropriadamente a língua, fazendo escolhas estilísticas (ALVES FILHO, 2011 p. 45).

O e-mail possui uma infinidade de temas, regularmente reconhecíveis pelas esferas que os utilizam, como saudades, boas novas, convites, lançamento de produtos, reclamações, novidades, dentre muitos outros. No tocante aos tratamentos dedicados aos e-mails, estes são, em geral, mais realísticos, no entanto, os e-mails analisados nessa pesquisa são didatizados, então em sua maioria apresentam temas fictícios, mas que relacionam uma atividade social cotidiana. Em relação ao tema e seu tratamento conferido, constatamos nas duas coleções:

Quadro 2: Regularidades sobre o conteúdo temático e tratamento conferido ao tema.

\begin{tabular}{|c|c|c|}
\hline & Tema & Tratamento conferido ao tema \\
\hline Atividade 1 & pedido de ajuda em pesquisa escolar & ficcional; científico \\
\hline Atividade 2 & pedido de ajuda em pesquisa escolar & ficcional; científico \\
\hline Atividade 3 & pedido de ajuda em pesquisa escolar & ficcional; científico \\
\hline Atividade 4 & novidade entre amigos & ficcional; factual; \\
\hline Atividade 5 & sugestão em estação de TV & ficcional; factual; meliorativo \\
\hline Atividade 6 & convite de férias & ficcional; factual; \\
\hline Atividade 7 & convite para uma festa & ficcional; factual; \\
\hline
\end{tabular}

\subsubsection{Temas e a temática das unidades didáticas}


A regularidade dos temas nas atividades 1, 2 e 3 reflete as temáticas interdisciplinares da unidade, entretanto, consideramos que um só tema para três atividades de escrita do $e$-mail enrijece sua ação criativa, pois enquanto gênero digital, o e-mail caracteriza-se “como eventos textuais altamente maleáveis, dinâmicos e plásticos” (MARCUSCHI, 2010, p.19), que podem variar em temas, dentre outros.Em referência ao tema das atividades 4, 5 e 6, percebemos que as atividades também refletem os temas abordados nas unidades do livro, mas houve a preocupação do autor em diversificar papeis sociais e eventos deflagradores em algumas atividades, o que é engrandecedor e espelha o e-mail na vida real.

\subsubsection{Tratamentos temáticos, simulações e finalidades didáticas}

Como todas as propostas de escrita do e-mail são na verdade simulações, os tratamentos temáticos refletem a ficcionalidade (eventos que simulam a ações cotidianas reais), afinal, os alunos deverão imaginar o contexto de situação, mergulhar em papeis para agirem discursivamente. Essa é uma tipicidade dos gêneros escolares e didáticos. Contudo, nas atividades 1, 2 e 3, elas desvelam-se pela cientificidade (por seu caráter de pesquisa escolar), em que o aluno deve ajudar o colega na pesquisa, enquanto que,na maioria das atividades (4, 5,6 e 7), as atividades são factuais aos usos do e-mail na vida social. Ressaltamos que os tratamentos conferidos ao tema, embora sejam diversificados em sua maioria, todos estão relacionados ao tema de cada unidade, e essa maioria prevalece numa única coleção.

\subsection{Papeis Sociais}

Os papeis sociais indicam a maneira como os interlocutores se portam na interação por determinados gêneros. Conforme Paré e Smart (1994, p.149 apud Carvalho, 2005, p.136), “as características dos papeis sociais delineiam o que pode ser dito, feito ou não por cada indivíduo”. Nesse sentido, os papeis sociais indicam escolhas estilísticas e intencionalidades. Nas atividades de escrita de e-mail no LD, encontramos os seguintes papeis:

Quadro 3: Regularidades sobre os papeis sociais

\begin{tabular}{|l|l|l|}
\cline { 2 - 3 } \multicolumn{1}{c|}{} & \multicolumn{1}{c|}{ Papel Social } & \multicolumn{1}{c|}{ Tipo de Interação } \\
\hline Atividade 1 & amigos (brasileiro e francês) & interlocutores fabricados \\
\hline Atividade 2 & amigos (brasileiro e francês) & interlocutores fabricados \\
\hline
\end{tabular}




\begin{tabular}{|l|l|l|}
\hline Atividade 3 & amigos (-) & interlocutores fabricados \\
\hline Atividade 4 & telespectador e estação de TV (-) & interlocutores fabricados \\
\hline Atividade 5 & amigos (americano e americano) & interlocutores fabricados \\
\hline Atividade 6 & amigos (-) & interlocutores fabricados \\
\hline Atividade 7 & amigos (brasileiro e estrangeiro) & interlocutores fabricados \\
\hline
\end{tabular}

\subsubsection{Interlocutores fabricados e interlocutores reais}

Na maioria das atividades, os papeis sociais são entre amigos, portanto, os interlocutores reais, alunos, interagem como fabricados, simulando essa interação. Entretanto, devemos esclarecer que na interação entre amigos, a relação normalmente é simétrica. Como os e-mails produzidos não serão lidos pelos amigos (interlocutores fabricados), mas por seus professores (interlocutores reais), a tendência é que a interação entre os interlocutores reais seja assimétrica, pois aos escreverem, os alunos interagirão com seus professores, avaliadores de sua escrita. Brito (1997 apud Menegassi, 2011, p.170) reconhece essa dificuldade da escola em criar situações realísticas, e aponta como problema a forte presença do interlocutor professor, que impossibilita do aluno fazer escolhas linguísticas baseadas em seu destinatário fabricado. A interação entre amigos há pouca monitoração da escrita, assim, pensamos que o ideal seria que nas práticas simuladas da escrita do e-mail, os livros propusessem trocas de mensagem entre alunos sem a preocupação na correção do mesmo.

\subsubsection{Interação entre diferentes nacionalidades}

Na maioria das atividades (1,2, 5 e 7$)$ a relação de amizade construída decorre entre nacionalidades diferentes, como brasileiros, franceses e americanos. Essa recorrência envolve os aspectos reais de utilização da língua, pois o inglês como língua estrangeira é utilizado internacionalmente pela maioria das pessoas. Portanto, utilizar a língua com interlocutores fabricados estrangeiros baseia-se numa função comunicativa real nos e-mails.

\subsection{Propósitos comunicativos}

Os propósitos comunicativos são as finalidades que os interlocutores possuem para agir discursivamente por um gênero (SWALES, 1990). Cada gênero possui suas regularidades 
de propósitos. O e-mail, por exemplo, possui multipropósitos que se tipificam conforme as necessidades, o contexto e os papeis sociais dos envolvidos na comunicação. Vejamos as regularidades sobre os propósitos comunicativos nas atividades:

\begin{tabular}{|c|c|c|c|}
\hline & Propósito didático / real & Propósito didático & Propósito real \\
\hline Ativ. 1 & $\begin{array}{l}\text { ajudar o amigo, fazendo } \\
\text { uma pesquisa escolar sobre } \\
\text { Santos Dummont }\end{array}$ & $\begin{array}{l}\text { usar a estrutura linguística e } \\
\text { temática da unidade }\end{array}$ & \\
\hline Ativ. 2 & $\begin{array}{l}\text { ajudar o amigo, fazendo } \\
\text { uma pesquisa escolar sobre } \\
\text { o Brasil e os países } \\
\text { vizinhos }\end{array}$ & $\begin{array}{l}\text { usar a estrutura linguística e } \\
\text { temática da unidade (implícito) }\end{array}$ & \\
\hline Ativ. 3 & $\begin{array}{l}\text { ajudar o amigo, fazendo } \\
\text { uma pesquisa escolar sobre } \\
\text { Einstein }\end{array}$ & $\begin{array}{lllll}\text { escrever } & \text { sobre } & \text { o } & \text { tema } & \text { da } \\
\text { unidade } & & & & \\
\end{array}$ & \\
\hline Ativ. 4 & & $\begin{array}{l}\text { usar a estrutura linguística e } \\
\text { temática da unidade (implícito) }\end{array}$ & $\begin{array}{l}\text { contar uma novidade para o } \\
\text { amigo }\end{array}$ \\
\hline Ativ. 5 & & $\begin{array}{l}\text { usar a estrutura linguística e } \\
\text { temática da unidade }\end{array}$ & $\begin{array}{l}\text { sugerir um artigo esportivo } \\
\text { sobre seu atleta favorito }\end{array}$ \\
\hline Ativ.6 & & $\begin{array}{l}\text { usar a estrutura linguística e } \\
\text { temática da unidade (implícito) }\end{array}$ & $\begin{array}{l}\text { convidar o amigo para passar } \\
\text { as férias }\end{array}$ \\
\hline Ativ.7 & & & $\begin{array}{l}\text { convidar o amigo para uma } \\
\text { festa }\end{array}$ \\
\hline
\end{tabular}

\subsubsection{Propósitos comunicativos e os conteúdos didáticos}

Percebemos que todas as atividades recorrem na utilização da temática da unidade, e na maioria delas (exceto atividade 3) exploram também a estrutura linguística. Evidenciamos que esse propósito da atividade é forçosamente didático, mas que em algumas atividades não chocam com os propósitos reais, por exemplo, na atividade 7, o propósito de escrever o e-mail para um amigo dar-se pelo convite de férias, de modo que o aluno possa usar a estrutura linguística da unidade. Esse propósito baseia-se no real uso que fazemos desse gênero. Envolvese assim um enfoque retórico e linguístico. Entretanto, na maioria das atividades percebemos que há um descompasso entre os propósitos (linguístico e real). Conforme Alves Filho (2011, p. 36), muitos gêneros do LD possuem foco gramatical, e não nas funções do gênero. Analisando as atividades 1,2,3,5 e 6,constatamos que essa finalidade gramatical ainda é recorrente nos LDs. Vejamos um exemplo: 


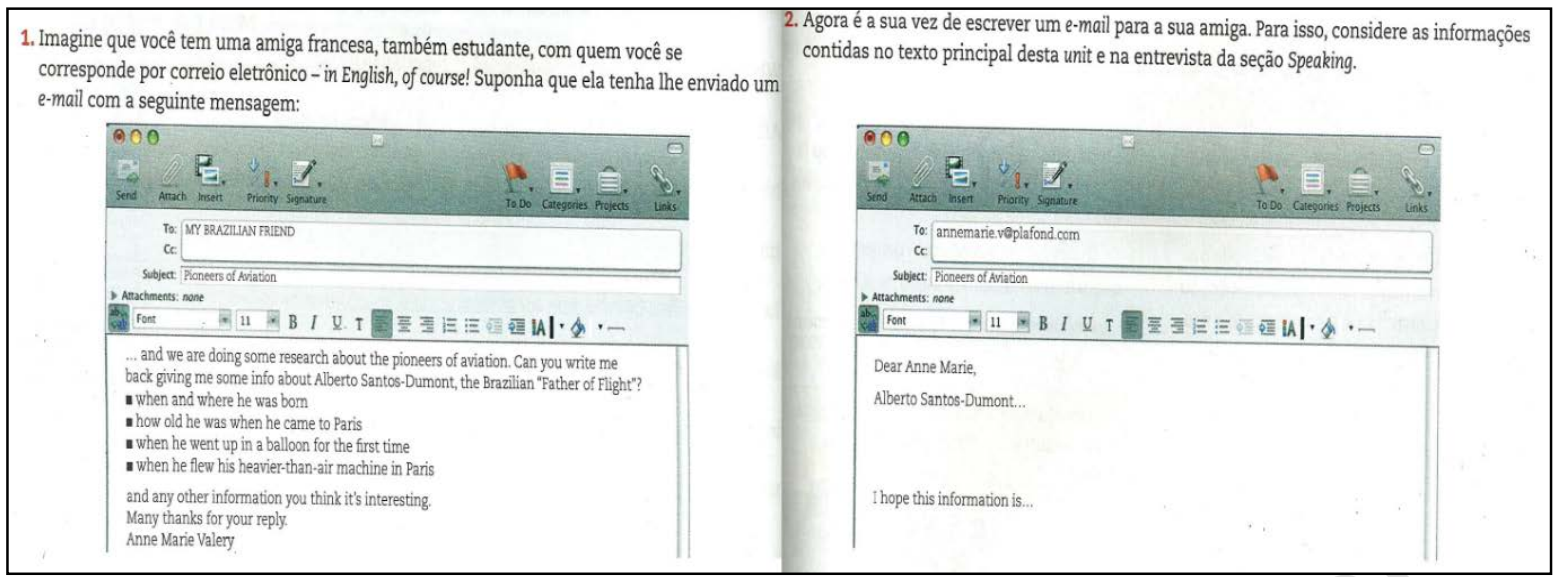

Fig. 1 Atividade 1.Fonte: Marques (2010a, p.76).

A atividade propõe que o aluno ajude a amiga francesa em sua pesquisa escolar sobre Santos Dumont. No corpo de sua mensagem, há direcionamentos gramaticais (when and where he was born; how old he was when he came to Paris;) para que o aluno utilize o tempo passado na resposta do e-mail.Percebemos que o gênero mais adequado para essas finalidades seriaa biografia e não o e-mail,pois o aluno deveria, na verdade, fazer uma descrição sobre a vida de Dumont, logo, consideramos que as propostas dessas atividades são didáticas, e a maioria não se fundamenta nas funcionalidades retóricas do $e$-mail na vida social.

\subsubsection{Propósitos implícitos, papeis e estilos}

Verificamos que nas atividades a maioria dos propósitos linguísticos, na verdade, são mascarados no interior das mensagens (atividades 1 , 2 e 3) ou através de palpites como o aluno deveria escrever(atividades 4, 5 e 6). Vejamos um exemplo:

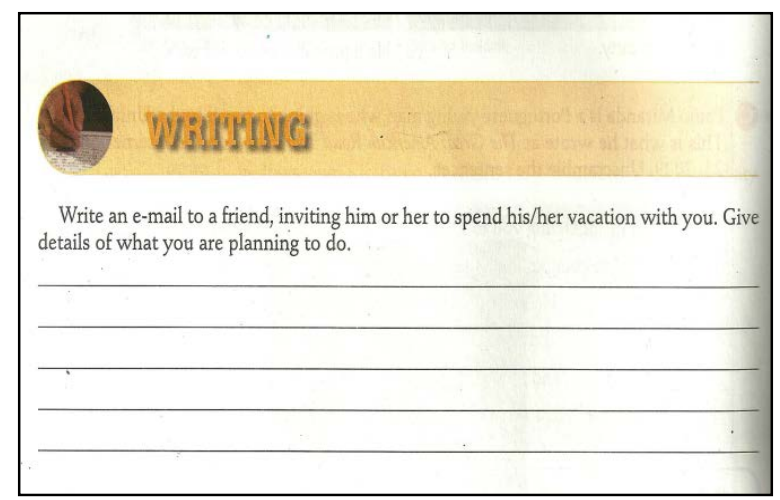

Fig.2 atividade 6. Fonte: Aun, Morais e Sansanovicz (2010a , p. 108). 
Nessa atividade, observamos claramente que o propósito está subtendido, e que na verdade, a atividade sugere que o aluno fale sobre o que fará nas férias, intencionando que o mesmo utilize o tempo futuro em inglês. É um propósito do LD fazer com o aluno se aproprie das estruturas de acordo com o contexto, baseados na abordagem sociointeracional. Mas, devemos salientar que numa situação real não nos preocuparíamos com a escrita naquele meio, principalmente quando os interagentes são amigos. Apenas duas atividades (2 e 3) pediram que os alunos observassem os recursos estilísticos típicos do e-mail, como carinhas e abreviações, portanto, não é um propósito regular que as atividades de escrita do e-mail no LD reflitam sobre a variedade linguística dos gêneros digitais.

\subsection{Estilos}

O estilo do gênero corresponde às regularidades linguísticas, lexicais, gramaticais que o mesmo apresenta. Segundo Bakhtin (1997, p.284), o estilo está intimamente ligado ao enunciado, e então ao gênero do discurso. Por isso o autor defende, e tantos outros, que a abordagem da língua deve ser situada nos contextos de utilização da mesma, percebendo as formas linguísticas mediante os usos sociais que fazemos.

As escolhas estilísticas do gênero e-mail variam de acordo com os interlocutores, por exemplo, em um e-mail recebido de um advogado, notamos que se regularizam por um estilo mais impessoal e com uma linguagem mais rebuscada, em outra situação, quando recebemos um e-mail de um irmão, poderá haver uma linguagem bem mais direta e recheada de coloquialismos.

\subsubsection{Escolhas estilísticas e propósitos didáticos}

É uma tendência nos e-mails de amigos a utilização de expressões, abreviações e gírias devido pouco monitorarem sua escrita. Todavia, verificamos que nas atividades analisadas os estilos são majoritariamente determinados pelos propósitos didáticos, e isso entra em conflito com os papeis sociais dos interlocutores fabricados: amigos. Destarte, a regularidade se dá numa variante que destoa daquela em que normalmente amigos se comunicam, pois, geralmente, utilizamos a linguagem menos monitorada nas mensagens pessoais, e as atividades evidenciam o conteúdo linguístico específico de cada unidade. Observemos um exemplo: 


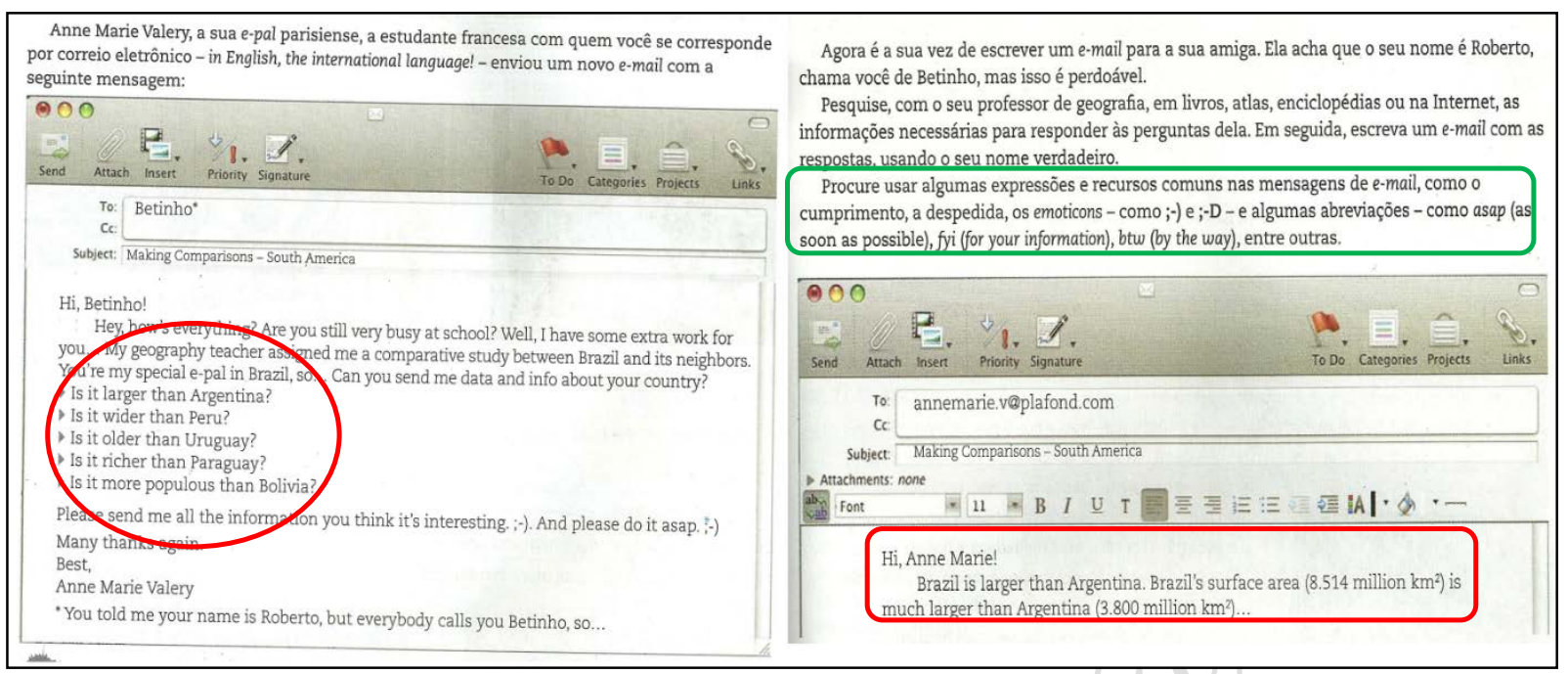

Fig.3 Atividade 2. Fonte: Marques (2010b, p.18).

Percebemos nessa atividade que as escolhas estilísticas são regidas pelos conteúdos linguísticos trabalhados na unidade. Em relação à variedade linguística da mensagem eletrônica, constatamos que as atividades 2 e 3 sugerem que os alunos possam se apropriar das mesmas, entretanto isso não foi percebido nas outras atividades, sendo assim, não é recorrente nas atividades a preocupação com essa variedade da língua regular na vida real entre contatos pessoais próximos, como amigos. Devemos ressaltar que na elaboração de um e-mail, dependendo dos interlocutores, não nos preocupamos de forma alguma com a escrita, assim é a língua em situação social, temos a competência em adequar nossas variantes para determinados interlocutores.

\subsection{Estrutura composicional}

A estrutura composicional refere-se as formas reconhecíveis dos gêneros envolvidos por suas características estilísticas e conteudistas que são tipificadas de acordo com as especificidades de cada esfera (BAKHTIN,1997, p. 279). Embora o e-mail possua sua regularidade, sua estrutura é bastante variável. Em e-mails mais formais é possível encontrar uma saudação, vocativo, corpo da mensagem, despedida e assinatura, mas na interação contínua, pode haver outras variedades. Independente dos participantes, os textos possuem dimensões e tipos textuais variados, podem ter diferentes gêneros intercalados como as piadas, 
fábulas, petições, notas fiscais eletrônicas, etc., tudo isso dependendo dos demais elementos que o regularizam.

\subsubsection{Apropriação da estrutura composicional}

Observamos que as atividades 1, 2 e 3 buscam fazer sempre com que os alunos respondam a uma mensagem já presente nas mesmas. Isso conduz a apropriação da estrutura composicional do $e$-mail pelos alunos, de forma que percebam que o $e$-mail, na verdade, tratase de uma escrita dialógica:
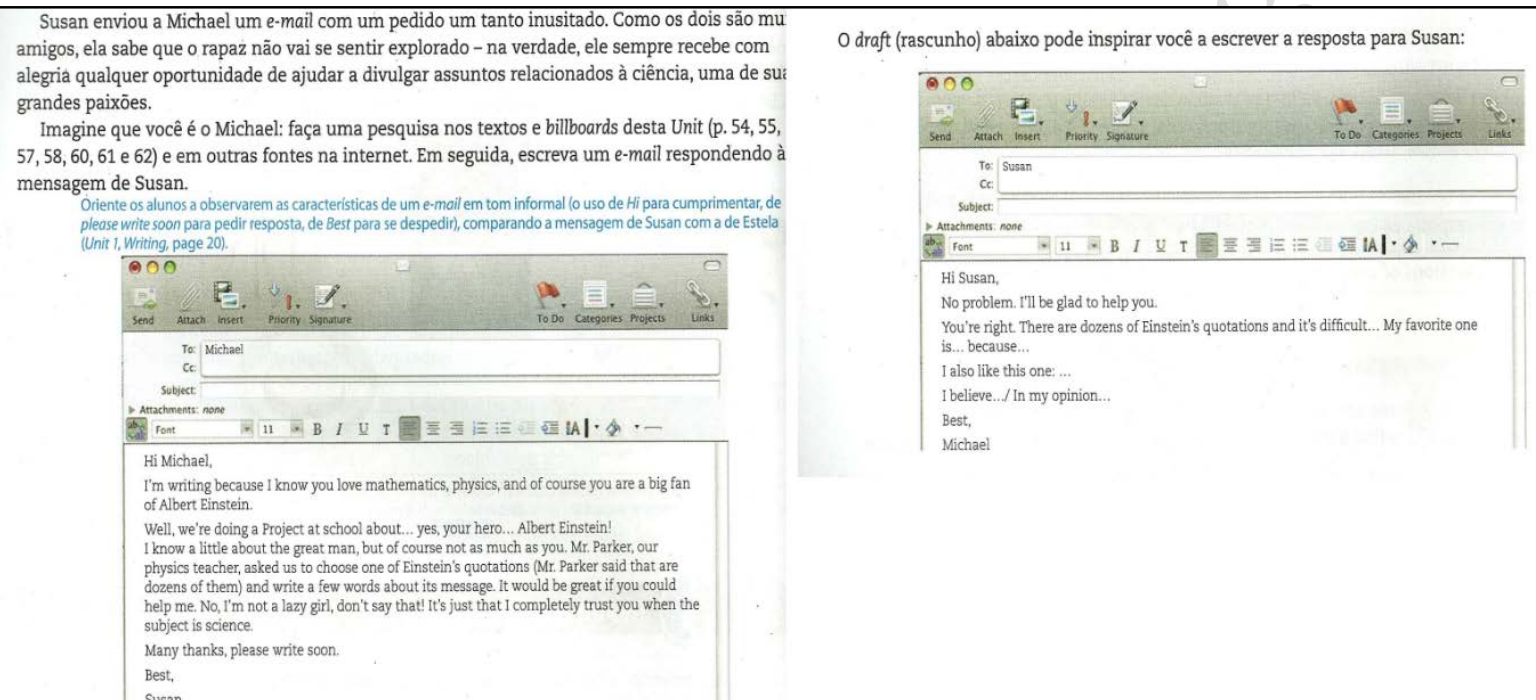

Fig. 4 Atividade 3. Fonte: Marques (2010c, p.64).

Essas atividades trazem o layout usual, de forma que o aluno possa simular como esse gênero acontece na virtualidade. Notamos ainda que nas mensagens a saudação inicial é a mesma para todos: “Hi!”, e os cumprimentos finais são os mesmos: “Best,”. Esses termos são regulares, mas como o livro propõe que os alunos aprendam a interagir em inglês, seria importante que houvesse uma variação entre essas formas de tratamento, pois não são as únicas que utilizamos nos e-mails.

Porém, essa representatividade é pequena e ocorre em apenas em uma coleção didática. Nas demais atividades (4,5,6 e 7) não há a apropriação da estrutura composicional. Nessas atividades, as mensagens são partidas inicialmente sempre do interlocutor aluno e o layout só é apresentado na atividade 4, nas demais apenas apresentam linhas que mais parecem a folha pautada do caderno do aluno ou uma folha de redação. Acreditamos que o layout seja 
importante para que o aluno possa simular essa interação mesmo que seja no livro, mas isso não é um fator agravante para que comprometa o $e$-mail enquanto sua função social. Verificamos que algumas composições já iniciam o corpo da mensagem diretamente:

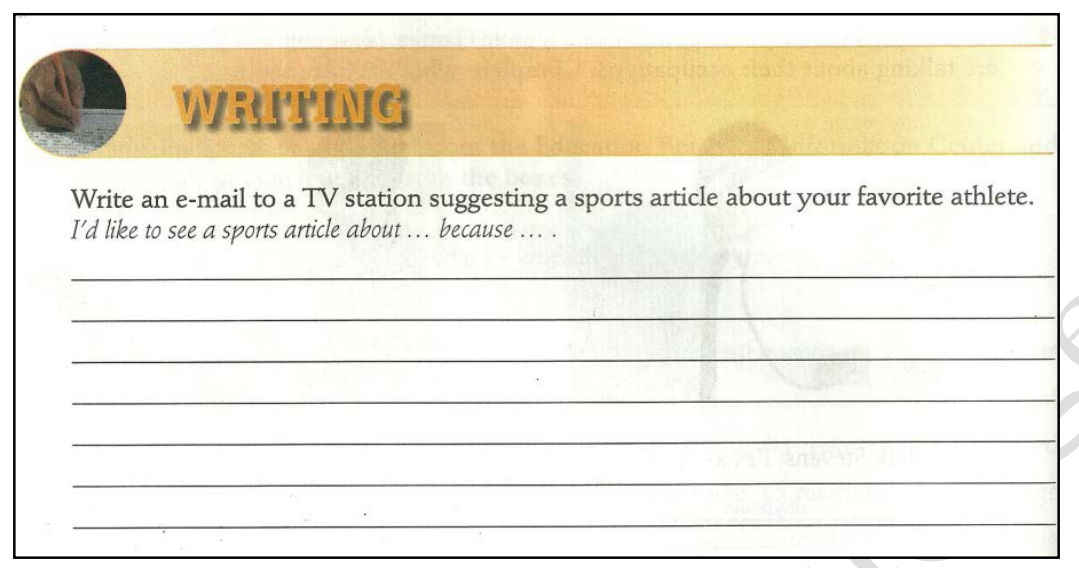

Fig.5 atividade 4. Fonte: Aun, Morais e Sansanovicz (2010a, p. 76).

Sabemos que isso pode ocorrer no e-mail, pois, dependendo dos atores e do envolvimento dos mesmos, eles podem ser diretos, contudo não é comum, principalmente iniciar o texto abruptamente como: "I'd like to see a sports article about...because...", geralmente somos diretos quando já tivemos algumas trocas de mensagem sobre o mesmo assunto. Portanto, consideramos que essa prática não se regulariza aos e-mails.

\section{Considerações finais}

Submersos no virtual, em que o tempo e o espaço são ressignificados, as interações comunicativas vêm contraindo novas formas sociais de interação mediante suas especificidades. Gêneros como o e-mail, complexos, fluidos e evoluídos de outros, tem nos proporcionados variações criativas da língua, sobretudo na escrita (CRYSTAL, 2006).

Concordamos com Schneuwly e Dolz (2004 apud AGUIAR, 2012, p.38) que os gêneros são essenciais para o ensino de produção escrita, deste modo, acreditamos que a esfera escolar necessita repercutir essas novas escritas contemporâneas, não se limitando a simulação de práticas orais e escritas do universo concreto (fora da web), mas também do universo digital. O livro didático, instrumento que norteia o processo de ensino e aprendizagem nas escolas, deve acompanhar essa efervescência, não só possibilitando o reconhecimento dos suportes, mas dos usos sociais que fazemos desses gêneros, dos papeis sociais que desenvolvemos etc. Nessa perspectiva, concordamos com Alves Filho (2011, p. 29): 
Poderíamos dizer, então, que conhecer apropriadamente um gênero implica também saber escolher qual conteúdo é apropriado, adequado e se ajusta a determinados propósitos comunicativos e em qual forma textual ele pode ser expresso de modo a se obter o sucesso desejado na ação comunicativa.

No presente artigo, analisamos as atividades de escrita do gênero e-mail em livros didáticos. Reconhecendo que esses, na verdade, são gêneros do discurso, e como tal possuem uma função social que é didatizar sequencialmente a aprendizagem de línguas, constatamos que essa função construída enunciativamente pelos seus autores repercutirá nos gêneros listados nos livros. Algumas tendências previsíveis, nesse sentido, foram percebidas, pois os propósitos das atividades se regularizam em aspectos linguísticos e temáticos de cada unidade didática, refletindo sobremaneira nos estilos dos gêneros a serem produzidos pelos alunos e nos papeis sociais dos interlocutores fabricados, que em sua maioria eram amigos estrangeiros.

A própria conjuntura escolar, e os papeis sociais desempenhados historicamente por professores e alunos, muitas vezes, não favorece uma escrita em que simule situações reais, pois a leitura do e-mail, não é exercida pelos interlocutores fabricados, mas por professores, que possuem tradicionalmente o papel de corrigir e avaliar. Logo, comprovamos que os livros didáticos embora já reflitam sobre os gêneros digitais, como o e-mail, ainda pouco espelham sobre as variedades linguísticas permitidas pelos usos síncronos e assíncronos da escrita digital, principalmente quando seus interlocutores são próximos e íntimos. Nisto, o gênero e-mail, nas atividades, revelam enfoques linguísticos enrijecidos às sequências didáticas e a escolha do mesmo não se baseia em sua função social, pois os eventos deflagradores, temas, propósitos, papeis e estilos conflitam-se, e não se regularizam, em sua maioria, no uso cotidiano que fazemos do e-mail. Mas, infelizmente, essa tendência não é o esperado, conforme as OCEM (2006, p.36):

Pode-se pensar na proposição de sequências didáticas que envolvam agrupamentos de textos, baseados em recortes relativos a: temas neles abordados; mídias e suportes em que circulam; domínios ou esferas de atividades de que emergem; seu espaço e/ou tempo de produção; tipos ou sequências textuais que os configuram; gêneros discursivos que neles se encontram em jogo e funções sociocomunicativas desses gêneros; práticas de linguagem em que se encontram e comunidades que os produzem.

Claramente, o livro didático deve propiciar o desenvolvimento pleno das habilidades integradas do aluno, principalmente em língua inglesa por se tratar de uma língua não materna, portanto, seu sequenciamento gradual linguístico deve ser contextualizado às práticas reais de utilização da língua seguindo os pressupostos sociointeracionais. Concordamos com Alves 
Filho (2011, p.67) quando diz que o ideal seria que a abordagem pudesse privilegiar os dois enfoques (linguístico e retórico) "quando elas se mostrarem adequadas aos seus propósitos pedagógicos”. Verificamos que poucas atividades puderam contemplar esses dois enfoques, na verdade, a maioria revela uma maior preocupação com o enfoque gramatical, cuja relação, muitas vezes, destoa da função comunicativa de um propósito.

Se os livros didáticos buscam fazer o uso das funções comunicativas de nossas interações contemporâneas norteados pelo ensino de gêneros do discurso, há de se preocuparem em refletir também sobre as outras variações que não seja a elitista. Dessa forma, a construção do gênero deve ser pensada em como articular todos os elementos que regularizam o gênero. Acreditamos e esperamos que os livros possam ser instrumentos de mediação que valorizem todas as formas letradas, variações estilísticas, buscando nos gêneros as funções regulares que utilizamos na vida real, pois pensamos que ao serem avaliados segundo critérios que busquem a melhor formação para os alunos, o livro de certa maneira conduz a formação contínua dos professores, trazendo-os a reflexão de que o gênero deva ser percebido em sua natureza sociorretórica.

\section{Referências bibliográficas}

AGUIAR, A. A. S. Gêneros textuais e produção de texto em inglês. In: DIAS, R.; DELL'ISOLA, R.L.P. (orgs.) Gêneros textuais: Teorias e práticas de ensino em LE. Campinas: Mercado de letras, 2012.

ALVES FILHO, F. Gêneros Jornalísticos: notícias e cartas de leitor no ensino fundamental. São Paulo: Cortez, 2011.

ARAÚJO, M. de S. Gêneros textuais e atividades de compreensão leitora: o que mostra o livro didático de inglês do ensino médio? In: DIAS, R.; DELL'ISOLA, R.L.P. (orgs.) Gêneros textuais: Teorias e práticas de ensino em LE. Campinas: Mercado de Letras, 2012.

ASKEHAVE, I.; SWALES, J. M. Genre identification and communicative purpose: a problem and a possible solution.Oxford: Applied Linguistics Journals, 2001, p.195-212. Disponível na web: doi:10.1093/applin/22.2.195. Acesso em: 31 de julho de 2013. crossref http://dx.doi.org/10.1093/applin/22.2.195

AUN, E.; MORAES, M. C. P. de; SANSANOVICZ, N. B. v.1,2 e 3.English for all.São Paulo: Saraiva, 2010.

BAZERMAN, C. Gêneros textuais, tipificação e interação. DIONÍSIO, A. P; HOFFNAGEL, J. C. (orgs.) Tradução: Judith Chambliss Hoffnagel.São Paulo: Cortez, 3ed., 2009. 
BAKHTIN, M. M. Estética da Criação Verbal. São Paulo: Martins Fontes, 1997.

BEZERRA, B. G. Gêneros introdutórios em ambiente virtual: uma (re) análise dos propósitos comunicativos. Linguagem em (Dis)curso, v. 9, p. 463-487, 2009.

BIASI-RODRIGUES, B. O papel do propósito comunicativo na análise de gêneros: diferentes versões. In: Simpósito Internacional de Estudos de Gêneros Textuais, 4, 2007, Tubarão. Anais. Tubarão: $\quad$ UNISUL, $2007 . \quad$ Disponível em http://www3.unisul.br/paginas/ensino/pos/linguagem/cd/Port/28.pdf> Acesso em: 31 de julho de 2013.

BUNZEN, C. O livro didático de português como um gênero do discurso: implicações teóricas e metodológicas. In: Anais do I Simpósio sobre o livro didático de Língua materna e estrangeira- I SILID. Rio de Janeiro: Edições Entrelugar, 2008.

BRASIL. Secretaria de Educação Básica. Orientações Curriculares Nacionais para o Ensino Médio:Linguagem, códigos e suas tecnologias. Brasília: Ministério da Educação, 2006.

PNLD 2012. Edital de Convocação para Inscrição no Processo de Avaliação e Seleção de Obras Didáticas para o Programa Nacional do Livro Didático 2012. Disponível em: http://www.fnde.gov.br/programas/livro-didatico/livro-didatico-editais. Acesso em: 30 de julho de 2013.

CARVALHO, G. "Gênero como ação social em Miller e Bazerman: o conceito, uma sugestão metodológica e um exemplo de aplicação”. In: MEURER, J. L.; BONINI, A.; MOTTA-ROTH, D. (orgs.) Gêneros: teorias, métodos, debates. Parábola, São Paulo, 2005.

CRYSTAL, D. Language and the Internet. New York: Cambridge University Press, 2ed., 2006. cross ref $\mathrm{http}: / / \mathrm{dx}$. doi.org/10.1017/cbo9780511487002

DEVITT, A. Writing Genres. Carbondale:Southern Illinois University Press, 2004.

KENSKI, V. M. Tecnologias e ensino presencial e a distância. 8.ed. Campinas: Papirus, 2003

MARCUSCHI, L. A.; XAVIER, A. C. Hipertexto e gêneros digitais: novas formas de construção de sentido. (orgs.). São Paulo: Cortez, 3ed, 2010.

MARQUES, A. On Stage: Ensino Médio. v.1.2,3.São Paulo: Ática, 2010.

MENEGASSI, R. J. O interlocutor nas propostas de produção textual no livro didático.Trab. linguist. apl. [online]. 2011, vol.50, n.1, pp. 169-187. ISSN 0103-1813. Disponível em: $<$ http://dx.doi.org/10.1590/S0103-18132011000100010>. Acesso em: 08 de agosto de 2013.

MILLER, C. R. Gênero como ação social. In: DIONÍSIO, J.; HOFFNAGEL, C. Gênero Textual, Agência e Tecnologia: estudos. São Paulo: Parábola, 2012. 
PAIVA, V. L. M. de O. E-mail:um novo gênero textual. In: MARCUSCHI, L. A.; XAVIER, A. C. Hipertexto e gêneros digitais: novas formas de construção de sentido. (orgs.). São Paulo: Cortez, 3ed, 2010.

PIRES, C. L. Um olhar sobre o comentário na Internet a partir da teoria de gêneros textuais. In: REINALDO, M. A.; MARCUSCHI, B.; DIONÍSIO, A. (Orgs.) Gêneros textuais: práticas de pesquisa e práticas de ensino. Recife: Ed.Universitária da UFPE, 2012.

REINALDO, M. A.; BEZERRA, M. A. Gêneros Textuais como prática social e seu ensino. In: REINALDO, M. A.; MARCUSCHI, B.; DIONÍSIO, A. (Orgs.) Gêneros textuais: práticas de pesquisa e práticas de ensino. Recife: Ed.Universitária da UFPE, 2012.

RODRIGUES, R. H. Os gêneros do discurso na perspectiva dialógica da linguagem. In: MEURER, J. L.; BONINI, A.; MOTTA-ROTH, D. (orgs.) Gêneros: teorias, métodos, debates. Parábola, São Paulo, 2005.

SOUSA, E. M. de F.; VIANA, L. D. C. Livro didático como gênero do discurso complexo. In: Anais do SILEL. Volume 2, Número 2. Uberlândia: EDUFU, 2011.

SWALES, J. M. Repensando gêneros: nova abordagem ao conceito de comunidade discursiva In: BEZERRA, B. G.; BIASI-RODRIGUES, B.; CAVALCANTE, M. M. Gêneros e sequências textuais. Recife: EDUPE, 2009.

Artigo recebido em: 19.10.2014

Artigo aprovado em: 03.02.2015 